Article

\title{
Research on a 20-Slot/22-Pole Five-Phase Fault-Tolerant PMSM Used for Four-Wheel-Drive Electric Vehicles
}

\section{Yi Sui, Ping Zheng *, Fan Wu, Bin Yu, Pengfei Wang and Jiawei Zhang}

School of Electrical Engineering and Automation, Harbin Institute of Technology, Harbin 150080, China; E-Mails: suiyi_hitee2005@163.com (Y.S.); wufan871226@126.com (F.W.); yubin1983@163.com (B.Y.); wpf6032@163.com (P.W.); zjwhit09@163.com (J.Z.)

* Author to whom correspondence should be addressed; E-Mail: zhengping@hit.edu.cn; Tel./Fax: +86-451-8640-3086.

Received: 15 December 2013; in revised form: 20 February 2014 / Accepted: 26 February 2014 / Published: 3 March 2014

\begin{abstract}
This paper presents a five-phase fault-tolerant permanent-magnet synchronous machine (PMSM) used for electric vehicles. In multiphase fault-tolerant PMSMs equipped with fractional-slot concentrated windings, excessive magneto-motive force (MMF) harmonics can lead to thermal demagnetization of the permanent magnets (PMs). In order to reduce the lower-order harmonics, the origins of the 2-pole harmonic in conventional winding configurations are investigated, and an unequal-turn winding configuration is applied to cancel the lower-order harmonics. The main electromagnetic performances of the unequal-turn winding configuration are investigated and compared with conventional winding topologies. Based on the principle of maintaining constant instantaneous power, the fault-tolerant control strategies for open-circuits of up to two phases are developed. All of the investigations are verified by finite element analysis (FEA) results.
\end{abstract}

Keywords: five-phase PMSM; fault-tolerant control; fractional-slot concentrated windings; unequal-turn winding configuration; lower-order harmonic; electric vehicle

\section{Introduction}

High fault-tolerant capability and high reliability are increasingly required in various applications. Owing to its high power density and high efficiency, a multiphase fault-tolerant permanent-magnet synchronous machine (PMSM) is often considered an excellent candidate for safety critical applications 
such as electric vehicles (EVs), marine propulsion and aerospace. In order to minimize the effect of fault phases on the other healthy phases, multiphase fault-tolerant PMSMs are designed to have low mutual inductances between different phases, and each phase of the machine is driven by a separate $\mathrm{H}$ bridge converter. A large phase inductance enables the terminal short-circuit current to be limited below its rated value. The above design features ensure the machine can be operated continuously under fault conditions.

In the past decades, PMSMs equipped with fractional-slot concentrated windings (FSCWs) have increasingly been used in EV applications [1-7]. With such windings the concentrated coils are wound either on adjacent or alternate teeth, which reduces the end winding length. Furthermore, a significant reduction of the copper loss is achieved, and the machine efficiency is improved [8-10]. Compared with traditional distributed windings, FSCW have low mutual inductances between phases, which meet the magnetic isolation demands of phase windings for multiphase fault-tolerant PMSM [11-14]. But FSCW also introduces many lower and higher order space harmonics, which have negative effects on machine performance, including localized saturation, eddy current losses in permanent magnets (PMs), possible resonance and noise, etc. The impacts of slot/pole combinations and magneto-motive force (MMF) harmonics on rotor eddy current losses in concentrated winding PM machines were analyzed by Aslan and Semail and Bianchi and Fornasiero, respectively [15-18]. By studying the interaction between MMF harmonics wavelengths and PM pole dimensions, a general analytical model of PM eddy-current losses is developed for comparison of multiphase PM machines [19,20]. The influence of post-fault control strategy and winding configuration on rotor losses is evaluated by both an analytical time-stepping model and a time harmonic current sheet method [21]. The impacts of slot harmonic and the number of phases on rotor losses in fractional-slot PM machines are investigated in [22]. Due to irregular MMF distribution, FSCW introduces unbalanced radial forces, and this causes considerable vibration and noise. The impacts of slot/pole combination choices on unbalanced radial forces and vibration modes are analyzed in [15]. The radial force density harmonics and vibration characteristics of fractional-slot PM machines are investigated in [23-26], and since FSCW machines are more susceptible to low frequency resonant vibrations, hence, for EV applications where a silent and smooth operation is required, the characteristics of the magnetic forces should be considered during the machine design process.

By reducing the lower-order MMF harmonics of FSCWs, machine performance can be improved to a certain extent, and several technical solutions have been developed to reduce or even cancel lower-order harmonics [27-29]. By shifting specific windings with a certain number of slots, the lower-order harmonics can be reduced a lot, but the working harmonic is also decreased, which is undesirable in the reduction process of lower-order harmonics. Besides, both lower- and higher-order harmonics can be reduced simultaneously by doubling stator slots and adding another set of windings [30]. Due to the overlapped winding structure, the mutual inductances are larger than those of concentrated winding topologies, and they are not suitable for fault-tolerant PMSMs. Aiming to improve machine efficiency, a winding configuration featured with different turns per coil side is also presented in [31], but the fault-tolerance performance of the proposed windings is not investigated, and for such kind of windings, further research focusing on their application in multiphase fault-tolerant PMSM and sub-harmonic cancelling principle are still needed. 
For four-wheel direct-drive EVs, low torque ripple enables low vibration and high driving comfort, but machine failures including open-circuit faults and short-circuit faults result in loss of torque or dangerous torque disturbance, which is detrimental to passenger safety, so continuous and smooth operation after faults is very important. In this paper, a five-phase in-wheel outer-rotor PMSM which shows advantages in high fault-tolerant ability and low torque ripple is proposed for high-reliability four-wheel-drive EVs. And the investigated multiphase PMSM adopts FSCW to obtain satisfactory fault-tolerant performance and low torque ripple, and these features make the machine quite competitive for four-wheel-drive EVs.

For PMSMs equipped with FSCWs, the MMF harmonics cause eddy currents in PMs, and this leads to a temperature rise. In order to protect PMs and improve machine reliability and efficiency, an unequal-turn winding configuration featuring different turns per coil side is applied to the investigated five-phase PMSM.

Due to the additional degrees of freedom, the five-phase PMSM has better reliability compared with conventional three-phase PMSM. A control strategy that enables post-fault operation of a five-phase PMSM is introduced. Based on the principle of maintaining constant instantaneous power, the phase currents for healthy phase windings are obtained by minimizing a cost function of copper loss. Under this scheme, the five-phase PMSM enables continuous and smooth operation with open-circuit faults of up to two phases. The fault-tolerant control strategy is verified by FEA.

\section{Machine Specification and Slot/Pole Combinations Choice}

In general, there are two different topologies for four-wheel-drive EVs: high-speed drive incorporating an additional gear box or low-speed direct drive. Table 1 summarizes some typical specifications of the electric drive systems, i.e., the commercial Prius and Protean Electric drive systems [32-34], the radial-flux PM hub machine developed by Rix and Kamper [35], and the direct-drive machine investigated in this paper.

Table 1. Some typical specifications of electric drive system.

\begin{tabular}{ccccc}
\hline Parameter & 2004 Prius & $\begin{array}{c}\text { Protean } \\
\text { Electric }\end{array}$ & $\begin{array}{c}\text { Radial-flux PM hub } \\
\text { machine }\end{array}$ & $\begin{array}{c}\text { Direct-drive } \\
\text { machine }\end{array}$ \\
\hline Peak output power (kW) & 50 & 80 & - & 24 \\
Continuous power (kW) & 30 & 54 & 10 & 12 \\
Base speed (rpm) & 1200 & 955 & 190 & 450 \\
Maximum speed (rpm) & 6000 & 1400 & 900 & 1200 \\
Number of stator slots & 48 & 72 & 30 & 20 \\
Number of poles & 8 & 64 & 40 & 22 \\
\hline
\end{tabular}

The 2004 Prius uses a high-speed machine with an additional gear box, so the number of poles is relatively low. The Protean Electric system and Radial-flux PM hub machine are direct-drive systems, using a high number of poles. In this paper, a four-wheel direct-drive scheme is used, so the number of poles is relatively high. Considering both fault-tolerant capability and power density, the slot/pole combinations for five-phase fault-tolerant PMSMs which satisfy $2 p=Q \pm 2$ (where $Q$ is number of slots, and $2 p$ is number of poles) are proposed [36]. The rotor losses on such slot/pole combinations are 
thoroughly investigated in $[15,19]$, and the analysis results indicate that in comparison with the low pole-number choice $(2 p=Q-2)$, the high pole-number choice $(2 p=Q+2)$ leads to higher rotor losses, which will reduce the power density. However, for the direct-drive outer-rotor machine used for four-wheel-drive EVs, the space limitation is serious, and compared with a low pole-number choice, the high pole-number choice results in a very shallow rotor core back and creates a "ring" type structure, and the center of the ring can be used to house the cooling system. Under a certain space limitation, a shallow core back of outer rotor enables a relative large air gap diameter, and this will improve the machine power density. The optimization dealt with this problem would require extensive model analysis and it is not concerned in this paper. Finally, the 20-slot/22-pole winding configuration is adopted in this paper.

\section{Research on 20-Slot/22-Pole Winding Topologies}

Conventionally, there are two winding topologies for the chosen slot/pole combination. One is single-layer winding configuration, and the other is double-layer winding configuration, as shown in Figure 1. For the chosen 20-slot/22-pole winding configuration, the winding factor of single-layer winding is 0.9877 , which is a little higher than that of double-layer winding, i.e., 0.9755. But double-layer winding features advantages in rotor losses and mechanical balancing $[15,16]$, combining the high-efficiency requirement of EV applications, the 20-slot/22-pole double-layer winding configuration is further investigated in this paper.

Figure 1. Conventional 20-slot/22-pole winding topologies: (a) single-layer winding configuration; (b) double-layer winding configuration.

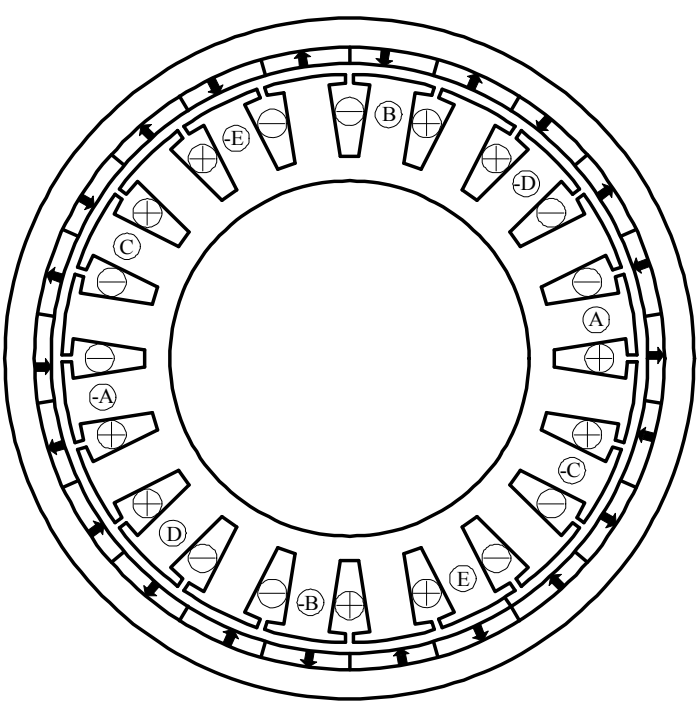

(a)

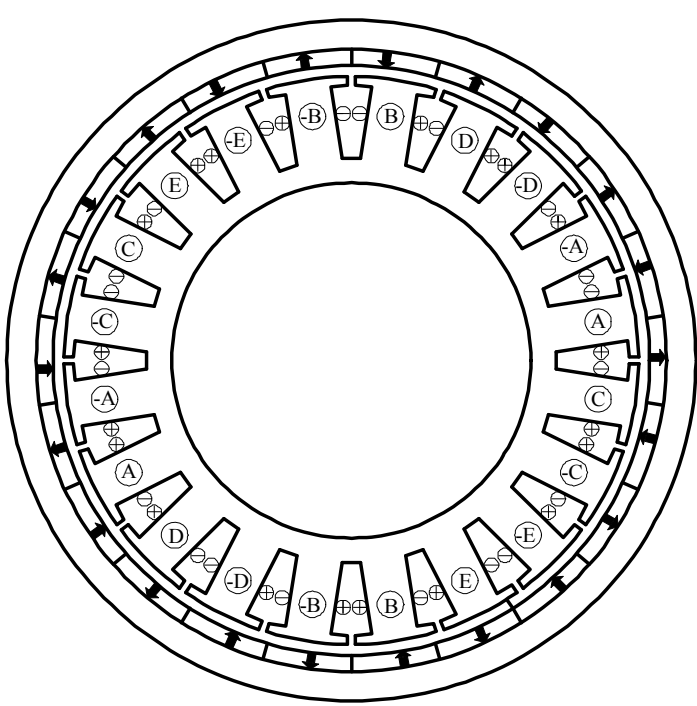

(b)

\subsection{Air-Gap Flux Density (Produced by Windings) of the Conventional 20-Slot/22-Pole Winding Topology}

In this section, electromagnetic performances of the 20-slot/22-pole double-layer winding configurations are investigated by FEA. Aiming to focus on the analysis of armature flux density, PMs are removed from the FEA models. The MMF distribution, air-gap flux density and their corresponding harmonic analysis of the double-layer winding configuration are shown in Figure 2. 
Figure 2. MMF and air-gap flux density (produced by windings) of the double-layer winding configuration: (a) MMF distribution; (b) harmonic analysis of the MMF distribution; (c) air-gap flux density; (d) harmonic analysis of the air-gap flux density.

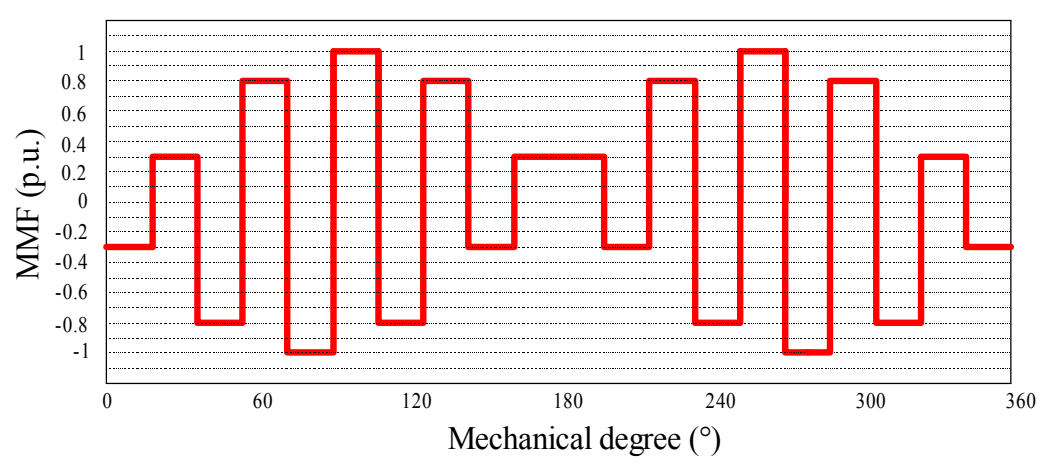

(a)

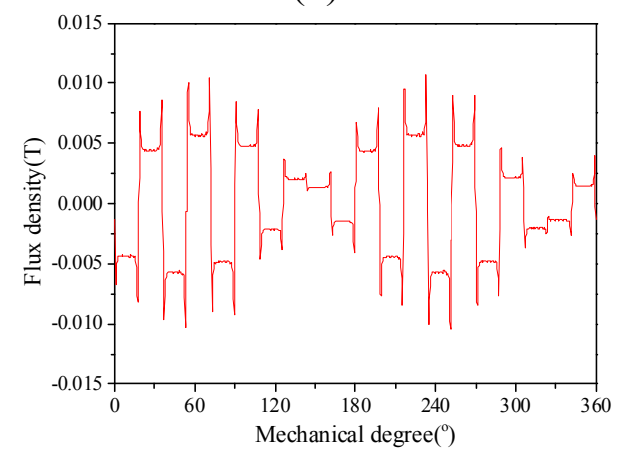

(c)

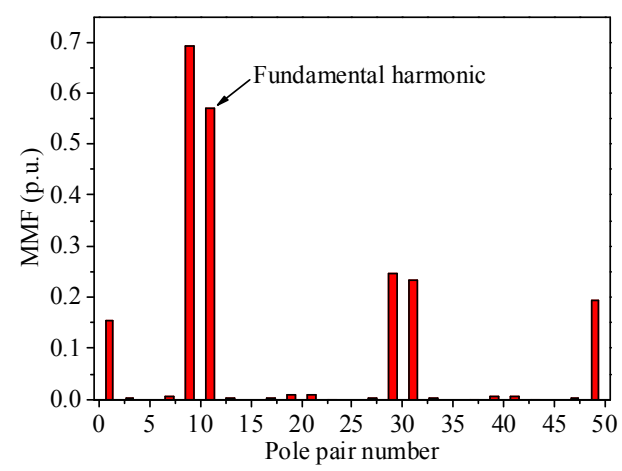

(b)

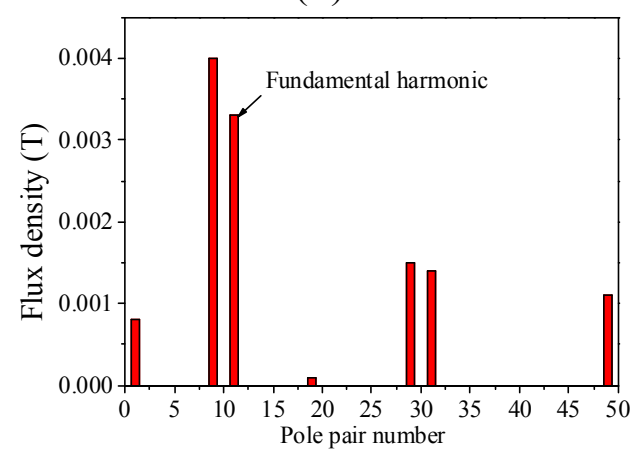

(d)

As shown in Figure 2, the MMF distribution indicates that an obvious 2-pole harmonic exists in the air gap, which is consistent with the calculated FEA results, and it verifies that the MMF analysis method is effective in the qualitative analysis process of armature flux distribution. The harmonic analysis shows that the 2-pole, 18-pole, and 22-pole space harmonics are dominant harmonics, but only the 22-pole harmonic interacts with the 22-pole PM field and generates constant torque. Generally, the armature space harmonic which interacts with the PM field and produces constant torque is named fundamental harmonic, and the space harmonics whose pole numbers are less than that of the fundamental harmonic are called sub harmonics. For the 20-slot/22-pole windings, the 22-pole space harmonic is fundamental harmonic, the 2-pole and 18-pole harmonics are sub harmonics.

The sub harmonics induce eddy current losses in the PMs, and the eddy-current losses are determined by the relative velocity (versus the fundamental harmonic) and amplitude of the harmonic. The relative velocities of the harmonics are in inverse proportion to their orders. Thus, among all of the sub harmonics, the 2-pole sub harmonic has the highest relative velocity with respect to the fundamental harmonic (eleven-fold rotating speed of the machine), and the 18-pole sub harmonic has a relative low speed but high amplitude, so both 2-pole and 18-pole sub harmonics generate considerable effect on rotor losses. In following section we focus on the investigation of the 2-pole sub harmonic. 


\subsection{The Origin of the 2-Pole Harmonic of the Conventional Winding Topologies}

With only one phase activated, the MMF and air-gap flux density of single-layer windings are shown in Figure 3.

Figure 3. MMF and air-gap flux density of single-layer windings (only one phase activated): (a) MMF distribution (b) air-gap flux density.

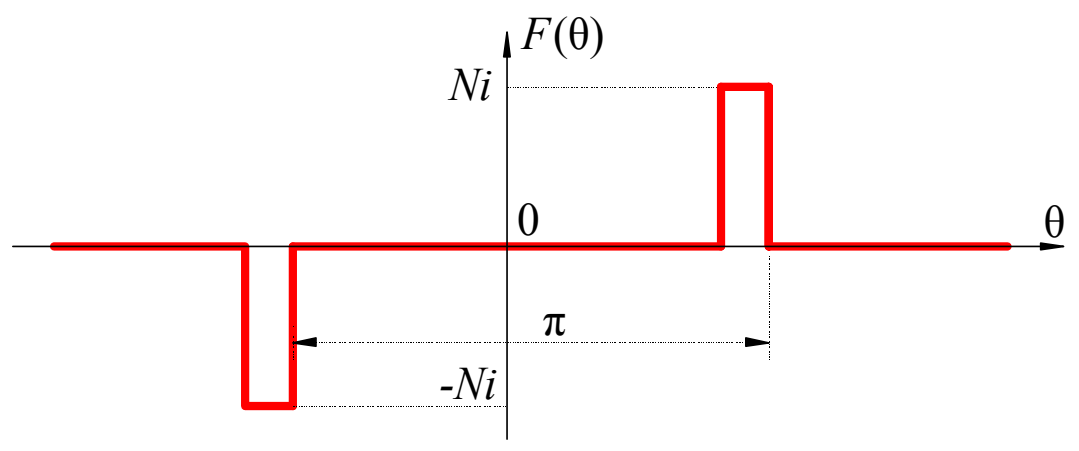

(a)

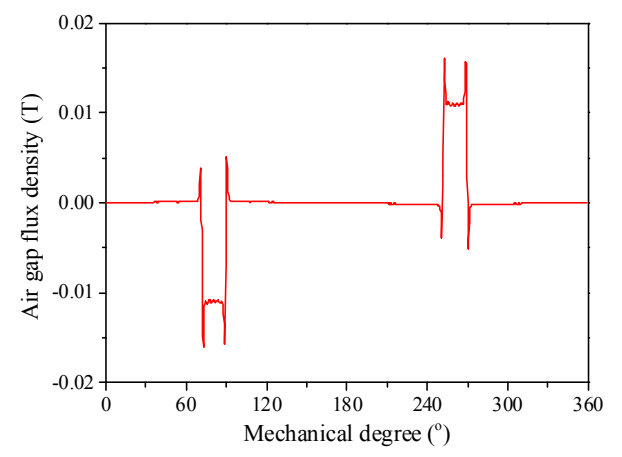

(b)

For the 20-slot single-layer winding configuration, there are only two coils of one phase, and they have opposite winding directions, so it is inevitable that a 2-pole harmonic exists in the air-gap MMF, and this is consistent with the FEA calculated air-gap flux density.

For the 20-slot double-layer winding configuration, there are four coils of one phase, the adjacent two coils have opposite winding directions, and one coil side of the adjacent two coils shares the same slot. With only one phase activated, the MMF of double-layer windings is shown in Figure 4.

Figure 4. Equivalent MMF analysis of double-layer windings (only one phase activated).
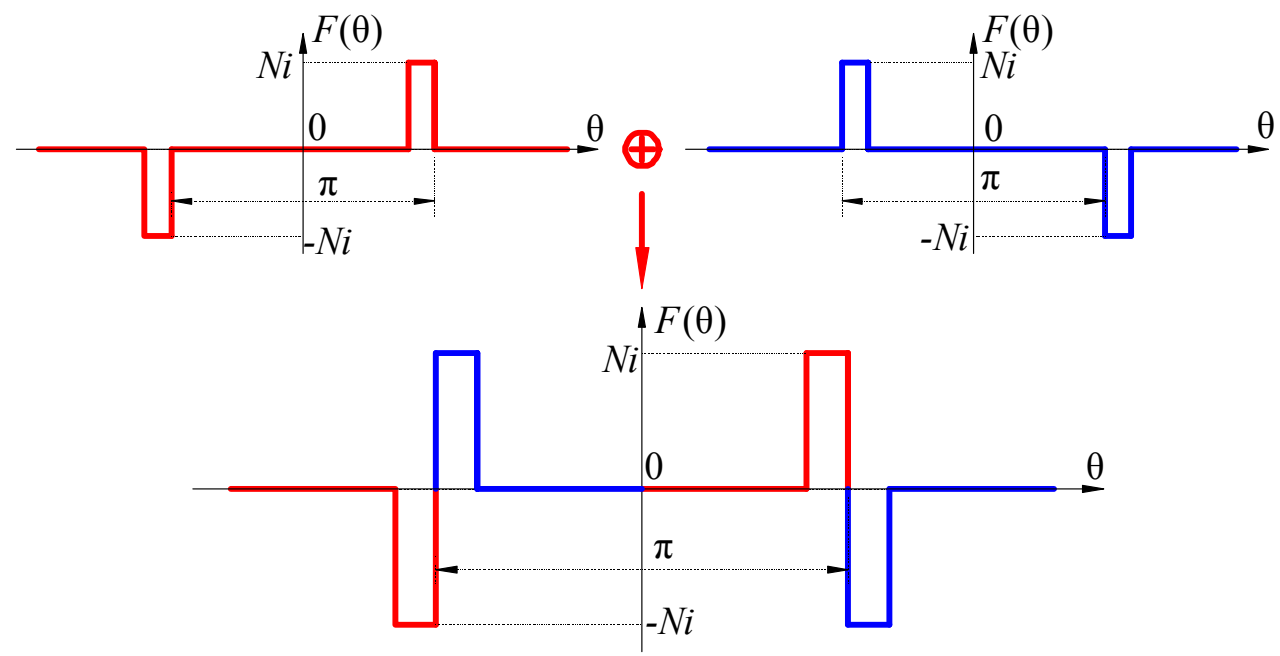

From the MMF point of view, double-layer windings can be equivalently considered as superposition of two single-layer windings whose winding directions are opposite, as shown in Figure 4, so the 2-pole harmonics in the two equivalent single-layer windings will suppress each other, then the 2-pole harmonic in double-layer windings is reduced. Since the adjacent two coils are wound on different teeth, there is a certain phase shift between the two equivalent single-layer windings, so 
the 2-pole harmonic cannot be reduced to zero in conventional double-layer windings, which is consistent with the analysis results of Section 3.1.

\subsection{The Unequal-Turn Winding Topology}

From the above analysis, we know that the 2-pole sub harmonic in conventional double-layer winding configuration cannot be reduced to zero. For the 2-pole sub harmonic, the wave crest of the 2-pole harmonic locates in the center of Area 1, and the wave trough of the 2-pole harmonic locates in the center of Area 2, as shown in Figure 5a.

Figure 5. MMF distributions (only one phase activated): (a) MMF of double-layer winding; (b) the introduced 2-pole MMF; (c) MMF of unequal-turn winding.

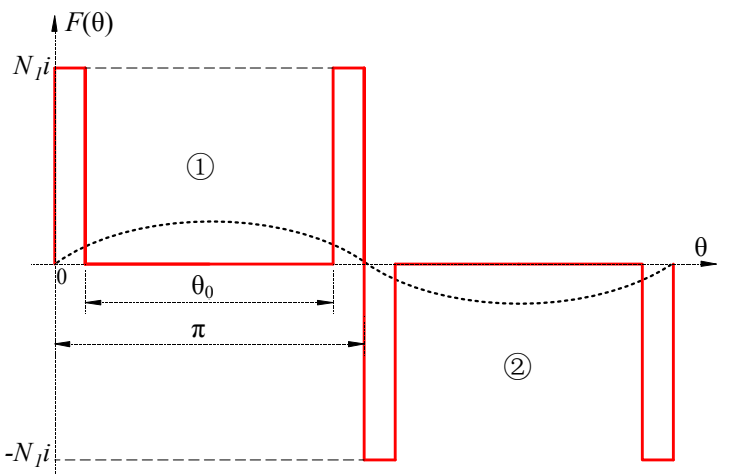

(a)

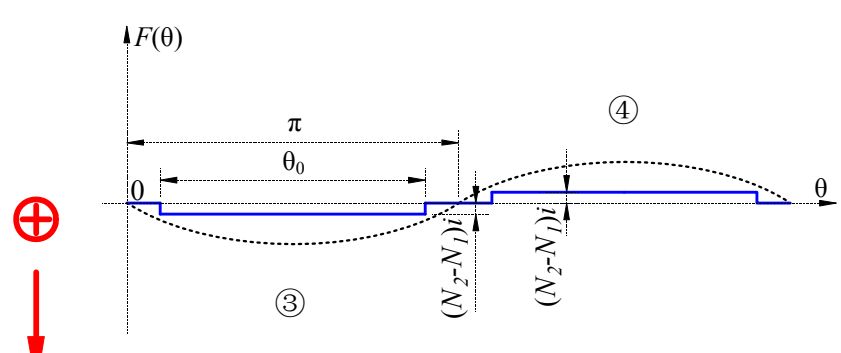

(b)

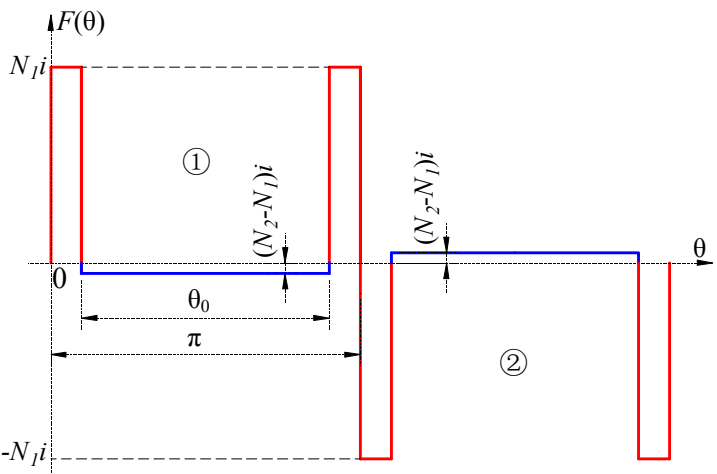

(c)

In order to reduce the 2-pole harmonic to zero, a "negative" 2-pole MMF is introduced to cancel the 2-pole sub harmonic, as shown in Figure 5b. Due to the introduced "negative" 2-pole MMF, the wave crest in Area 1 and wave trough in Area 2 can be canceled. The introduced "negative" 2-pole MMF can be realized by adopting unequal-turn winding topology, as shown in Figure 5c and Figure 6. Different from conventional winding configurations, the number of turns per coil side is different for the unequal-turn winding configuration. The manufacturing of unequal-turn winding is a little different from that of conventional winding, and the winding coils with different turns per coil side can be realized by winding only one side of the last turn. $N_{1}$ donates turn number of coil sides in the slots which contain coils of the same phase, $N_{2}$ donates turn number of coil sides in the slots which contain coils of different phases, and the relation between $N_{1}$ and $N_{2}$ is [31]:

$$
N_{2}=N_{1}+1 \text { and } 50 \% \leq N_{1} / N_{2} \leq 100 \%
$$


Figure 6. The unequal-turn winding topology.

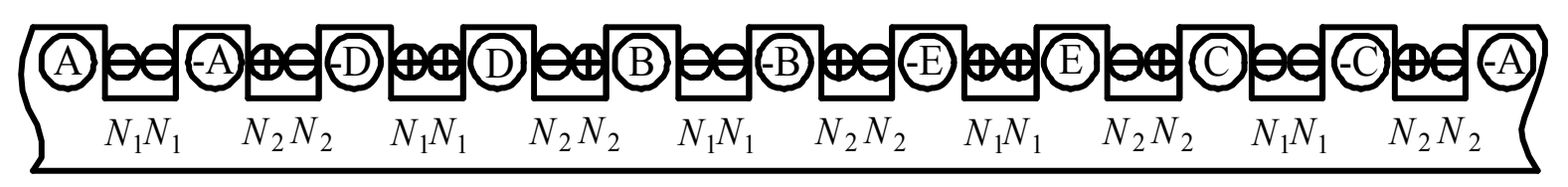

\section{Performance Comparison of the Conventional and Unequal-Turn Winding Topologies}

\subsection{Winding Factor of the Unequal-Turn Winding Topology}

The winding factor of the unequal-turn winding topology cannot be calculated using the classic formula like the conventional winding topology. An improved slot-vector diagram is developed to calculate the winding factor of the unequal-turn windings. Slot-vector diagram represents the electromotive force (EMF) induced in the conductors of each slot, and it is useful to study the harmonics of different orders, i.e., sub harmonics, fundamental harmonic, and high-order harmonics. For the studied 20-slot/22-pole winding configuration, the slot-vector diagram is shown in Figure $7 \mathrm{a}$.

Figure 7. Slot-vector diagram of the 20-slot/22-pole unequal-turn winding configuration: (a) slot-vector diagram of fundamental harmonic; (b) universal slot-vector diagram.

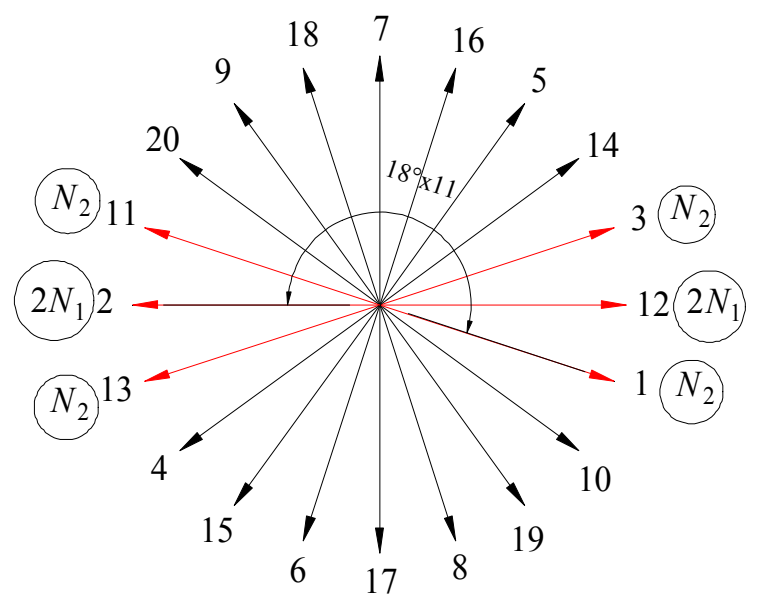

(a)

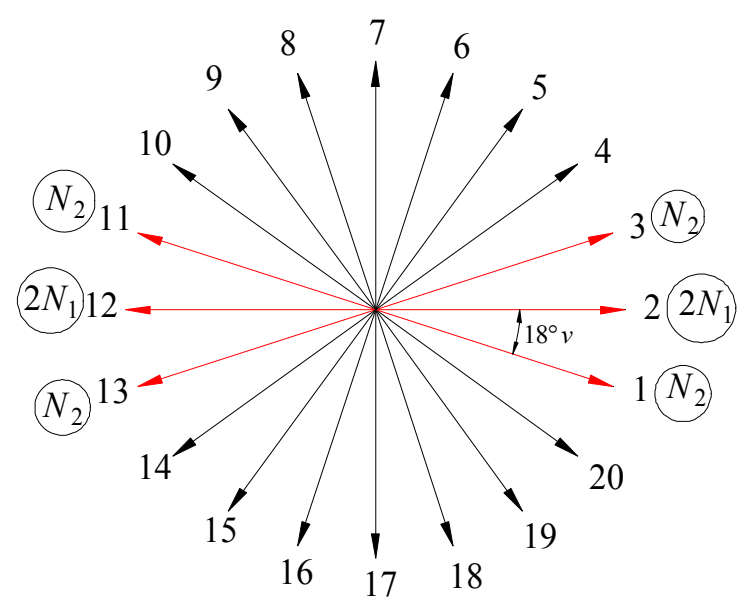

(b)

The resultant phasor of the fundamental harmonic is given by the sum of the phasors $1,-2,3,-11$, $12,-13$, the amplitudes of the phasors $1,3,11$, and 13 are all $N_{2}$, the amplitudes of both the phasors 2 and 12 are $2 N_{1}$. Winding factor of the fundamental harmonic equals the ratio between the amplitude of the resultant phasor and the sum of amplitude of the phasors 1, 2, 3, 11, 12, and 13.

The winding factor of other harmonics can also be investigated by the slot-vector diagram. Since the winding connection has been fixed by the fundamental harmonic (as shown in Figure 7a), the resultant phasor of the $v$-th harmonic is given by the sum of the phasors $1,-2,3,-11,12$ and -13 , as shown in Figure $7 \mathrm{~b}$. Winding factors of the other harmonics equal the ratios between the amplitude of the resultant phasor and the sum of amplitudes of the phasors 1, 2, 3, 11, 12 and 13. In fact, Figure $7 \mathrm{~b}$ is a universal slot-vector diagram for calculating winding factors of the unequal-turn winding configuration. For example, when $v=11$, Figure $7 \mathrm{~b}$ is the same as Figure $7 \mathrm{a}$; when $v=1$, winding factor of the 2-pole sub-harmonic can be calculated. 
Then winding factor for the unequal-turn winding topology can be described as:

$$
k_{w}=\frac{N_{2} \cdot \cos (\pi \cdot v / 10)-N_{1}}{N_{2}+N_{1}}
$$

The winding factors of the 2-pole harmonic and the fundamental harmonic vary with the ratio between turns of different coil sides, as shown in Figure 8.

Figure 8. The winding factors $v s . N_{1} / N_{2}$ : (a) Winding factor of the 2-pole harmonic;

(b) Winding factor of the 22-pole harmonic.

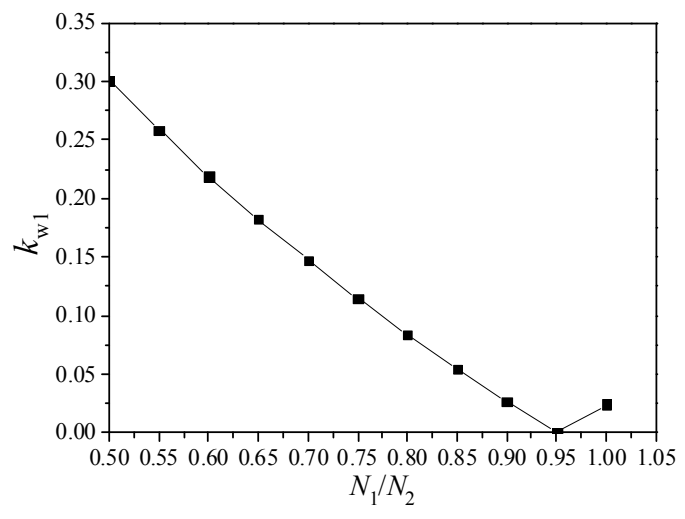

(a)

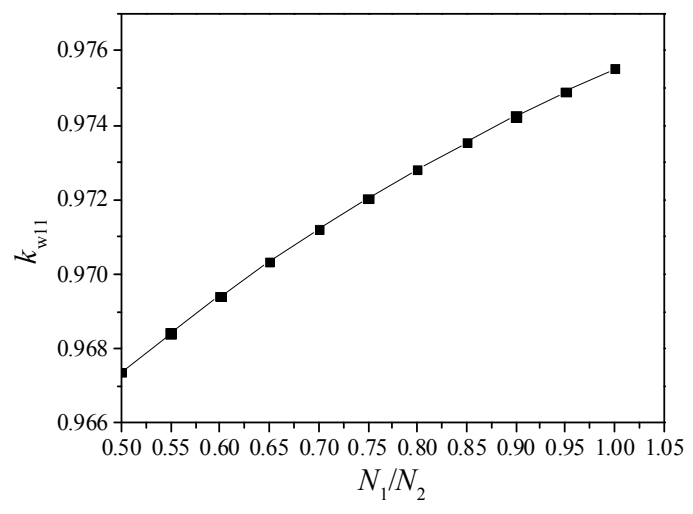

(b)

It is shown that the 2-pole harmonic is reduced to zero at the optimal point with $N_{1} / N_{2}=0.95$, and the fundamental harmonic is reduced by $0.06 \%$. Also the relation between $N_{1}$ and $N_{2}$ meets Equation (1), so $N_{1}$ is 19 , and $N_{2}$ is 20 .

\subsection{Comparison of the Air-Gap Flux Densities (Produced by Windings) between the Conventional and} Unequal-Turn Winding Topologies

With the optimum turn ratio of different coil sides, the winding factors and amplitudes of the air-gap flux densities for the unequal-turn windings are calculated, as shown in Table 2. The winding factors and amplitudes of the air-gap flux densities for conventional winding topologies are also listed.

Table 2. Winding factors and the amplitudes of air-gap flux density (produced by windings) for different 20-slot/22-pole winding configurations.

\begin{tabular}{cccccccccc}
\hline \multirow{2}{*}{$\boldsymbol{v}$} & \multicolumn{3}{c}{ Single layer } & \multicolumn{3}{c}{ Double layer } & \multicolumn{3}{c}{ Unequal-turn with $\boldsymbol{N}_{\mathbf{1}} / \boldsymbol{N}_{\mathbf{2}}=\mathbf{1 9 / 2 0}$} \\
\cline { 2 - 9 } & $\boldsymbol{k}_{\boldsymbol{w} v}$ & $\boldsymbol{B}_{\boldsymbol{v} \boldsymbol{m}}(\mathbf{m T})$ & p.u. & $\boldsymbol{k}_{\boldsymbol{w} v}$ & $\boldsymbol{B}_{\boldsymbol{v} \boldsymbol{m}}(\mathbf{m T})$ & p.u. & $\boldsymbol{k}_{\boldsymbol{w}}$ & $\boldsymbol{B}_{\boldsymbol{v} \boldsymbol{m}}(\mathbf{m T})$ & p.u. \\
\hline 1 & 0.1564 & 5.3 & 1.56 & 0.0245 & 0.8 & 0.24 & 0.0005 & 0 & 0 \\
9 & 0.9877 & 4.1 & 1.21 & 0.9755 & 4 & 1.21 & 0.9749 & 4 & 1.21 \\
11 & 0.9877 & 3.4 & 1 & 0.9755 & 3.3 & 1 & 0.9749 & 3.3 & 1 \\
\hline
\end{tabular}

$B_{v m}$ is the amplitude of air-gap flux density (produced by windings).

For the single-layer winding configuration, the amplitude of the 2-pole harmonic is 1.56 times of the fundamental harmonic, and for the conventional double-layer winding configuration, the 2-pole harmonic reduces to $24 \%$ of the fundamental harmonic. With the optimum turn ratio of different coil sides, the 2-pole harmonic is cancelled in the unequal-turn winding configuration. The air-gap flux 
densities of the conventional double-layer and unequal-turn winding configuration are compared, as shown in Figure 9. The FEA results indicate that the lower-order harmonic with 2 poles is cancelled and the fundamental harmonic nearly unchanged, which verifies the effectiveness of the unequal-turn winding configuration on reducing the 2-pole sub harmonic.

Figure 9. Comparison of air-gap flux densities of the conventional double-layer and unequal-turn winding configurations: (a) air-gap flux density; (b) harmonic analysis.

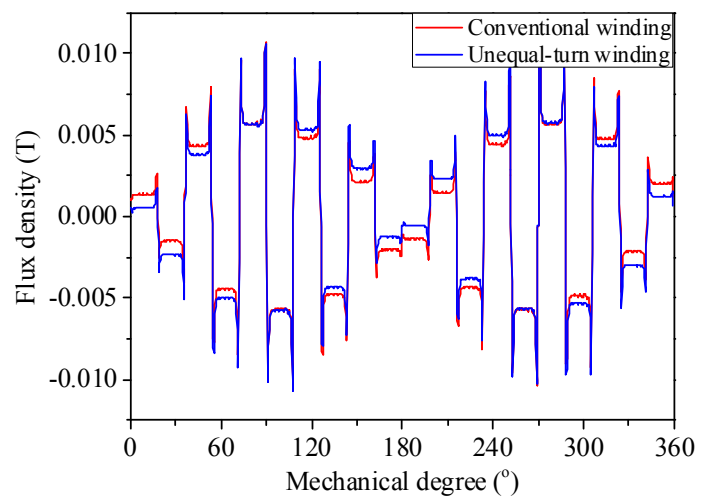

(a)

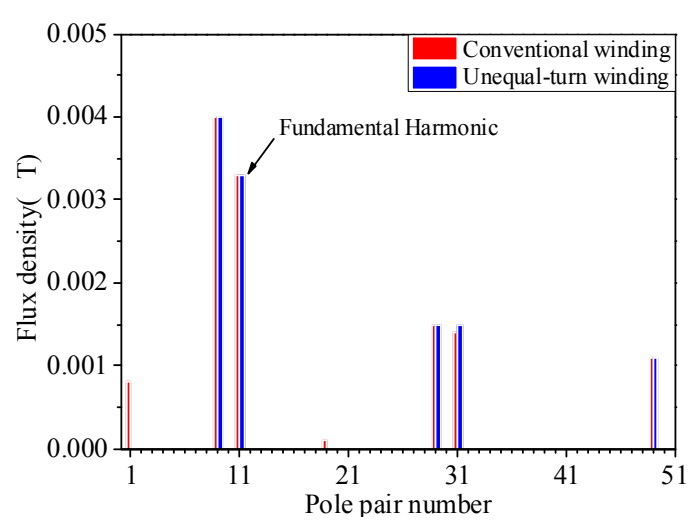

(b)

\subsection{Comparison of Mutual Inductances between Conventional and Unequal-Turn Winding Topologies}

For multiphase fault-tolerant PMSM, low mutual inductance between phases is a key requirement. In order to compare the mutual inductances of the unequal-turn winding configuration with those of the conventional winding topologies, the static magnetic fields of the conventional and unequal-turn winding configurations with PMs removed and only one phase windings activated (Phase A in this paper) are calculated, the flux distributions are shown in Figure 10.

For single-layer winding configuration, non-wound teeth are named fault-tolerant teeth, the flux linkage in the fault-tolerant teeth is leakage flux of Phase A which links through slot openings. Since the flux which is activated by Phase A does not link to the other four phase windings, the magnetic isolation between different phases is quite effective, and it meets the low mutual inductance demand of fault-tolerant PMSM.

For double-layer winding configuration, all teeth are wound, the slot-opening flux leakage of Phase A couples with Phases C and D, so it can be predicable that the mutual inductances of double-layer winding configuration are larger than those of single-layer winding configuration. And for double-layer winding configuration, the mutual inductances between Phase $A$ and Phases $C / D$ are larger than those between Phase A and Phases B/E.

For the unequal-turn winding configuration, parts of the flux of Phase A couples with Phases $\mathrm{C}$ and $\mathrm{D}$, the coupled flux composes of slot-opening flux leakage and flux linked through the air gap, and there is only slot-opening flux leakage coupled with other phases in conventional double-layer winding configuration, so it can be predicable that the mutual inductances of the unequal-turn winding configuration are larger than those of the conventional double-layer winding configuration. 
Figure 10. Flux distributions (only one phase windings activated): (a) single-layer winding; (b) double-layer winding; (c) unequal-turn winding.

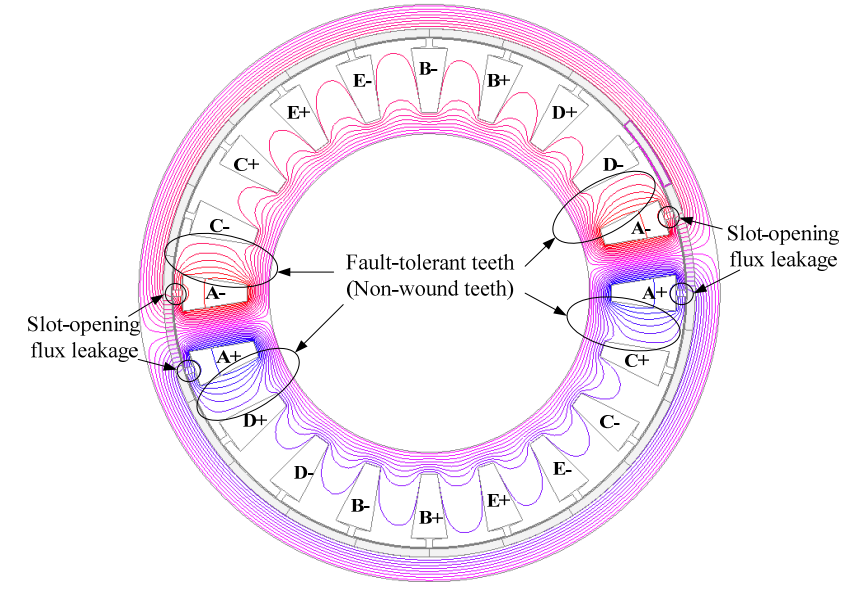

(a)

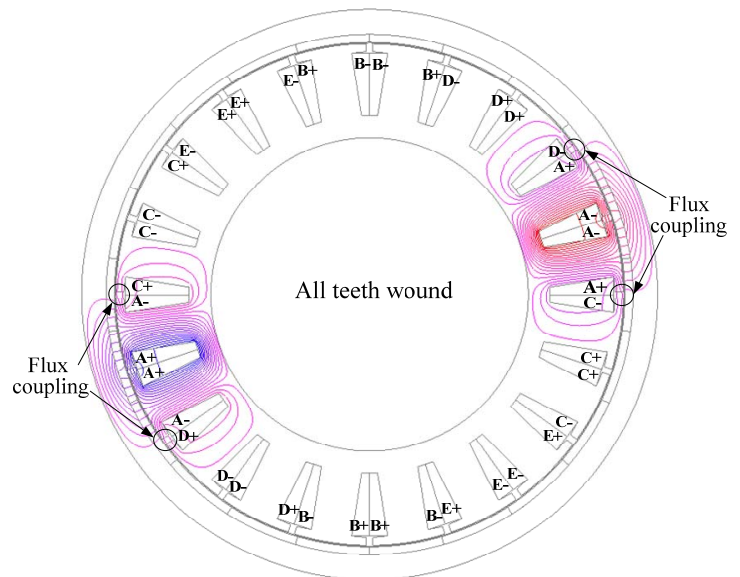

(b)

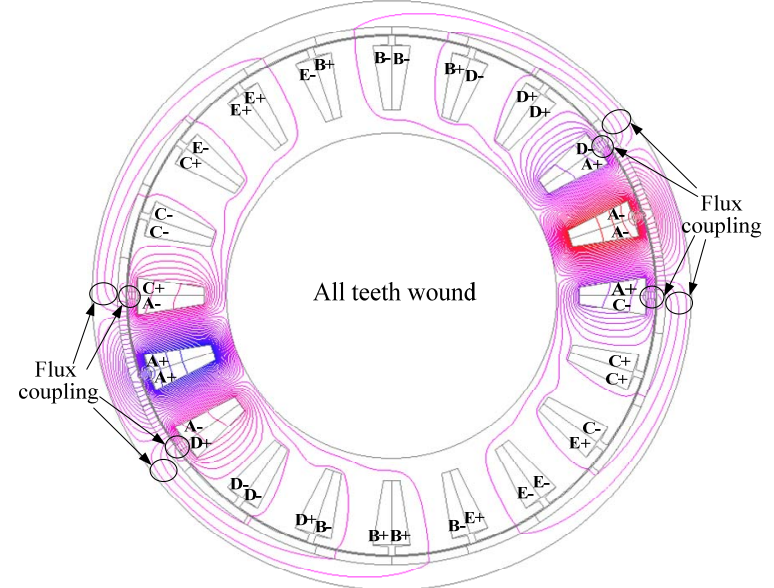

(c)

The inductance parameters of the conventional and unequal-turn winding configurations are calculated by FEA, as shown in Table 3 .

Table 3. Comparison of inductances between different winding topologies.

\begin{tabular}{cccccc}
\hline Windings layouts & $\boldsymbol{L}_{\mathrm{AA}}(\mathbf{m H})$ & $\boldsymbol{M}_{\mathbf{A B}}(\mathbf{m H})$ & $\boldsymbol{M}_{\mathrm{AC}}(\mathbf{m H})$ & $\boldsymbol{M}_{\mathrm{AD}}(\mathbf{m H})$ & $\boldsymbol{M}_{\mathrm{AE}}(\mathbf{m H})$ \\
\hline Single-Layer & 1.782 & 0.004 & 0.013 & 0.013 & 0.004 \\
Double-Layer & 1.067 & 0 & 0.084 & 0.084 & 0 \\
Unequal-Turn & 1.092 & 0 & 0.091 & 0.091 & 0 \\
\hline
\end{tabular}

$L_{\mathrm{AA}}$ is self-inductance of Phase $\mathrm{A}, M_{\mathrm{AB}}, M_{\mathrm{AC}}, M_{\mathrm{AD}}$, and $M_{\mathrm{AE}}$ are mutual inductances between Phase $\mathrm{A}$ and Phases B, C, D, and E, respectively.

It can be seen from Table 2 that the mutual inductances between Phase A and Phases $\mathrm{B}$ and $\mathrm{E}\left(M_{\mathrm{AB}}\right.$ and $\left.M_{\mathrm{AE}}\right)$ are almost zero for all of the three investigated schemes. For the single-layer, double-layer and unequal-turn winding configurations, the mutual inductances between Phase $\mathrm{A}$ and Phases $\mathrm{C}$ and $\mathrm{D}\left(M_{\mathrm{AC}}\right.$ and $\left.M_{\mathrm{AD}}\right)$ are $0.73 \%, 7.9 \%$ and $8.3 \%$ of the self-inductances $\left(L_{\mathrm{AA}}\right)$, respectively.

The single-layer winding configuration features high self-inductance and low mutual inductances, the mutual inductances of double-layer winding configuration are larger than those of the single-layer 
winding configuration. Compared with the double-layer winding configuration, the mutual inductances of the unequal-turn winding configuration are a little larger, but the 2-pole sub harmonic in the unequal-turn winding configuration is completely eliminated, so the unequal-turn winding configuration is very promising.

\subsection{Comparison of Radial Force Density Distributions between Conventional and Unequal-Turn} Winding Topologies

For the conventional and unequal-turn winding configurations, the radial force density distributions under both no-load and load conditions, and the corresponding harmonic analysis omitting the dc component are calculated, as shown in Figures 11 and 12. The no-load curves of conventional and unequal-turn winding configurations are the same. The radial force harmonic distribution in Figure $12 \mathrm{~b}$ is normalized to the amplitude of the 22nd-order force harmonic in Figure 12a.

Figure 11. Radial force density distribution under no-load and load conditions: (a) no-load;

(b) single-layer winding under load condition; (c) double-layer winding under load condition; (d) unequal-turn winding under load condition.

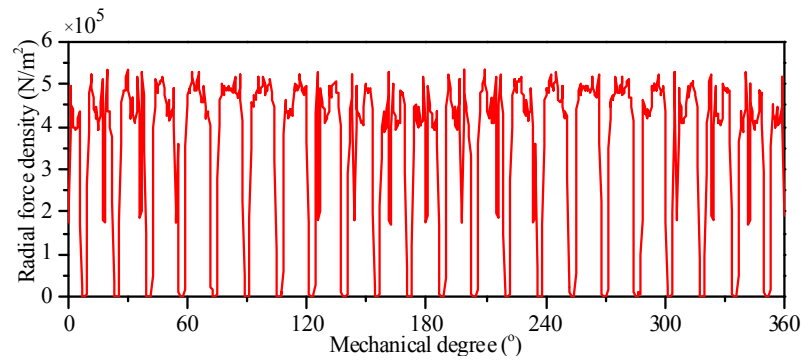

(a)

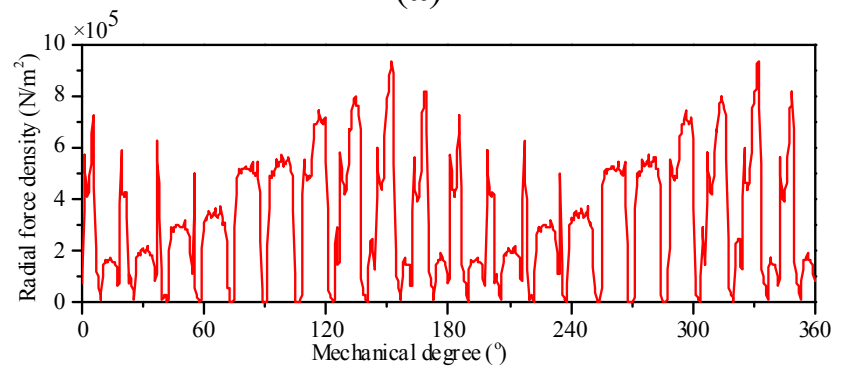

(c)

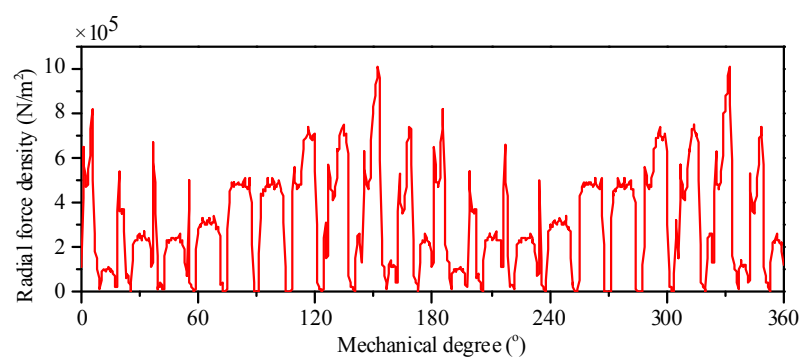

(b)

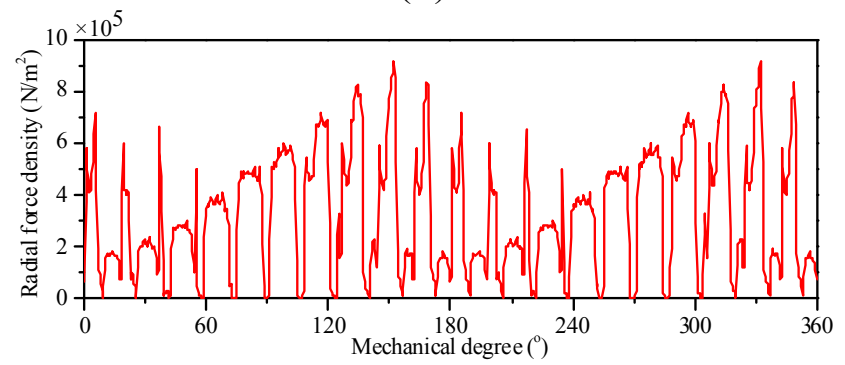

(d)

The no-load radial force density contains harmonics of orders 2, 20, 22, 44, etc., and the strongest 22nd and 44th order harmonics are consequences of the 11th working harmonic, i.e., the 22-pole PM field. For the conventional single- and double-layer windings, the dominant harmonics of load radial force density are with orders 2, 10,12, 20, 22, 44, etc. Compared with the conventional single- and double-layer windings, the amplitudes of load radial force density harmonics of unequal-turn windings are lower, such as the 2nd, 10th, 12th and 20th order harmonics, etc. It is worth noting that the load radial force density contains a strong 2nd-order harmonic, and this strong harmonic can be clearly observed in Figure 11b-d. Since the machine structure is stiffer to short-wave distortion which corresponds to high order vibration mode, so the 2nd-order harmonic is the most detrimental to the 
machine strength, and compared with the conventional winding topologies, the 2nd-order harmonic of unequal-turn winding is reduced, which alleviates the harm of this harmonic.

Figure 12. Harmonic analysis of radial force density distribution under no-load and load conditions: (a) no-load; (b) harmonic comparison of the conventional and unequal-turn windings.

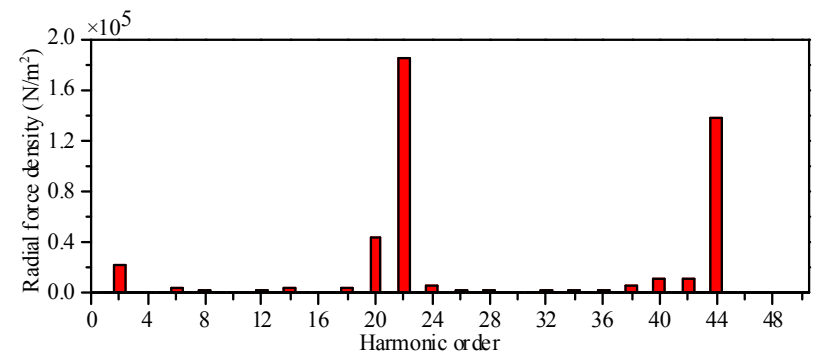

(a)

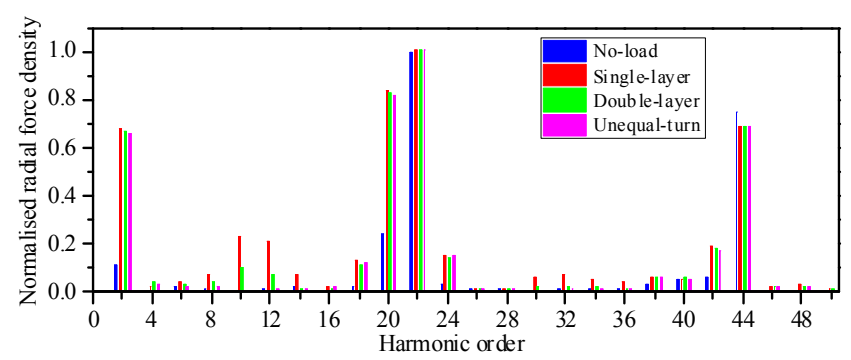

(b)

\subsection{Electromagnetic Performance Comparison of the Conventional and Unequal-Turn Windings}

Three five-phase 20-slot/22-pole PMSM schemes featuring single-layer, double-layer and unequal-turn winding configurations have been designed and calculated using the commercial FEA software Ansoft Maxwell. For the three machine schemes, the stator lamination, efficient length, air gap length, width and thickness of magnet, and electromagnetic power are the same. Hence, direct electromagnetic performance comparison for the three schemes is possible. The magnet conductivity is $\sigma=625,000 \mathrm{~s} / \mathrm{m}$. In order to calculate the impact of skin effect on PM losses, high mesh density in magnets are adopted. Based on the 2-D FEA models, the PM losses are calculated without consideration of axial segmentation, circumferential segmentation, and 3D effect. The machine performances under the rated speed of $450 \mathrm{rpm}$ are compared, as shown in Table 4.

Table 4. Performance comparison of the conventional and unequal-turn winding machines.

\begin{tabular}{ccccccccc}
\hline $\begin{array}{c}\text { Winding } \\
\text { layouts }\end{array}$ & $\begin{array}{c}\text { Rated speed } \\
(\mathbf{r p m})\end{array}$ & $\begin{array}{c}\text { Frequency } \\
\mathbf{( H z )}\end{array}$ & $\begin{array}{c}\text { Torque } \\
\mathbf{( N \cdot m )}\end{array}$ & $\begin{array}{c}\text { Torque } \\
\text { ripple } \mathbf{( \% )}\end{array}$ & $\begin{array}{c}\text { Core loss } \\
\mathbf{( W )}\end{array}$ & $\begin{array}{c}\text { PM loss } \\
(\mathbf{W})\end{array}$ & $\begin{array}{c}\text { Copper } \\
\text { loss (W) }\end{array}$ & $\begin{array}{c}\text { Efficiency } \\
(\%)\end{array}$ \\
\hline Single-layer & 450 & 82.5 & 254.6 & 1.1 & 79.8 & 274.9 & 380 & 94.23 \\
Double-layer & 450 & 82.5 & 254.2 & 0.55 & 72.5 & 258.9 & 376.5 & 94.42 \\
Unequal-turn & 450 & 82.5 & 254.6 & 0.44 & 71.2 & 247.9 & 373.5 & 94.54 \\
\hline
\end{tabular}

All of the three winding configurations compared in Table 4 have smooth torques, which is beneficial to improve the driving comfort of EVs. Compared with the single-layer winding configuration, the core loss and PM loss of the double-layer winding configuration are reduced by $9.1 \%$ and $5.8 \%$, and its efficiency is enhanced. By comparison with the double-layer winding configuration, the core loss and PM loss of the unequal-turn winding configuration are reduced by $1.8 \%$ and $4.2 \%$, respectively. Among the three investigated schemes, the unequal-turn winding configuration has the highest efficiency, and it is more suitable for EV applications. 


\section{Open-Circuit Fault-Tolerant Control of the Unequal-Turn Winding Machine}

As an electric drive system operates under some circumstances, over-voltage or over-current of the system will cause damage to the power electronic devices of converter, and it will lead to open-circuit faults of stator windings, then torque ripple increases and performance of the system degrades. Due to additional degrees of freedom, the five-phase PMSM can continue to work under open circuits of up to two phases without adding additional hardware and just by modifying the control strategy. In this section, a current control strategy that enables the five-phase unequal-turn winding PMSM to operate smoothly with loss of up to two phases is introduced.

\subsection{One-Phase-Open Fault}

Assume Phase E is open-circuited, as shown in Figure 13.

Figure 13. Schematic diagram of one-phase-open fault.

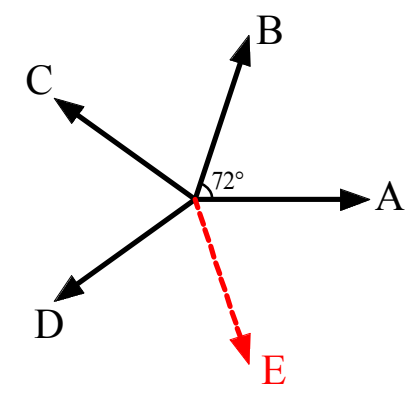

The electromagnetic power of PMSM equals the sum of instantaneous power of each of the stator windings. The instantaneous power of each of the stator windings can be calculated by the phase current and the EMF induced in the windings. Through maintaining the sum of instantaneous power unchanged, the output electromagnetic power under open-circuit fault conditions can be the same as that under healthy conditions. For a certain speed, the output torque in open-circuit fault conditions can be kept the same as that before the fault happened. Under restrictive condition of keeping the output torque unchanged, the optimal currents for healthy phase windings can be calculated by minimizing a cost function of copper loss:

$$
P_{w}=\sum_{j=0}^{3}\left(i_{j}\right)^{2}+\lambda\left[T_{d}-\frac{1}{\omega} \sum_{j=0}^{3} E_{0} \cos \left(\theta-j \frac{2 \pi}{5}\right) i_{j}\right]
$$

$i_{j}$ is instantaneous current in the healthy phase windings, $j=0,1,2$ and 3 represent Phases $\mathrm{A}, \mathrm{B}, \mathrm{C}$ and $\mathrm{D}$, respectively. $E_{0}$ is peak value of back EMF, $T_{d}$ is the demanded torque, and $\omega$ is speed, $\lambda$ is Lagrange multiplier.

The problem dealt with open-circuit fault-tolerant control of the unequal-turn winding PMSM is transformed into a conditional extreme problem. Based on the Lagrange multiplier method, Equation (4) is obtained: 


$$
\left[\begin{array}{ccccc}
2 & 0 & 0 & 0 & -\frac{E_{0}}{\omega} \cos \theta \\
0 & 2 & 0 & 0 & -\frac{E_{0}}{\omega} \cos \left(\theta-\frac{2 \pi}{5}\right) \\
0 & 0 & 2 & 0 & -\frac{E_{0}}{\omega} \cos \left(\theta-\frac{4 \pi}{5}\right) \\
0 & 0 & 0 & -\frac{E_{0}}{\omega} \cos \left(\theta+\frac{4 \pi}{5}\right) \\
\frac{E_{0}}{\omega} \cos \theta & \frac{E_{0}}{\omega} \cos \left(\theta-\frac{2 \pi}{5}\right) & \frac{E_{0}}{\omega} \cos \left(\theta-\frac{4 \pi}{5}\right) & \frac{E_{0}}{\omega} \cos \left(\theta+\frac{4 \pi}{5}\right) & 0
\end{array}\right]=\left[\begin{array}{c}
i_{a} \\
i_{b} \\
i_{c} \\
i_{d} \\
\lambda
\end{array}\right]=\left[\begin{array}{c}
0 \\
0 \\
0 \\
0 \\
T_{d}
\end{array}\right]
$$

Through solving Equation (4), the optimal currents for healthy phase windings are obtained, as shown in Equation (5):

$$
\left[\begin{array}{c}
i_{a} \\
i_{b} \\
i_{c} \\
i_{d}
\end{array}\right]=\left[\begin{array}{c}
\frac{\omega T_{d} \cos (\theta)}{2 E_{0}[1+\cos (\pi / 5) \cos (2 \pi / 5) \cos (2 \theta-\pi / 5)]} \\
\frac{\omega T_{d} \cos (\theta-2 \pi / 5)}{2 E_{0}[1+\cos (\pi / 5) \cos (2 \pi / 5) \cos (2 \theta-\pi / 5)]} \\
\frac{\omega T_{d} \cos (\theta-4 \pi / 5)}{2 E_{0}[1+\cos (\pi / 5) \cos (2 \pi / 5) \cos (2 \theta-\pi / 5)]} \\
\frac{\omega T_{d} \cos (\theta+4 \pi / 5)}{2 E_{0}[1+\cos (\pi / 5) \cos (2 \pi / 5) \cos (2 \theta-\pi / 5)]}
\end{array}\right]
$$

From Equation (5), we can find that the peak values of the calculated currents in fault conditions are larger than those in healthy conditions, which indicates an increased cost and converter capacity. For a five-phase fault-tolerant PMSM system used for EV applications, the operation under fault-conditions is an occasional case and small-probability event, and it is a waste to prevent occasional faults at the cost of increasing cost and converter capacity. Thus, in order not to improve the converter capacity, peak values of the calculated phase currents for healthy phase windings are scaled in the same proportion to achieve the same peak current values as the ones before faults happened. In fact, part of the output electromagnetic power is sacrificed. The currents for healthy phase windings and the torque performances are calculated and verified by FEA, as shown in Figure 14 and Table 5.

Figure 14. Phase currents and electromagnetic torque under one-phase-open fault: (a) currents for healthy phase windings; (b) torque.

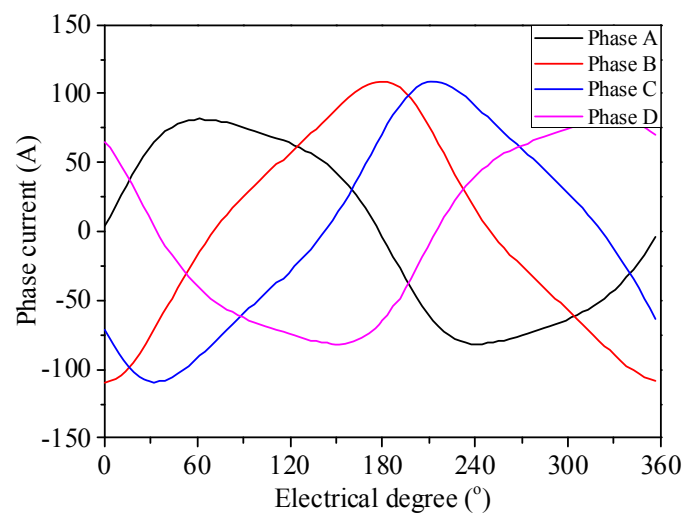

(a)

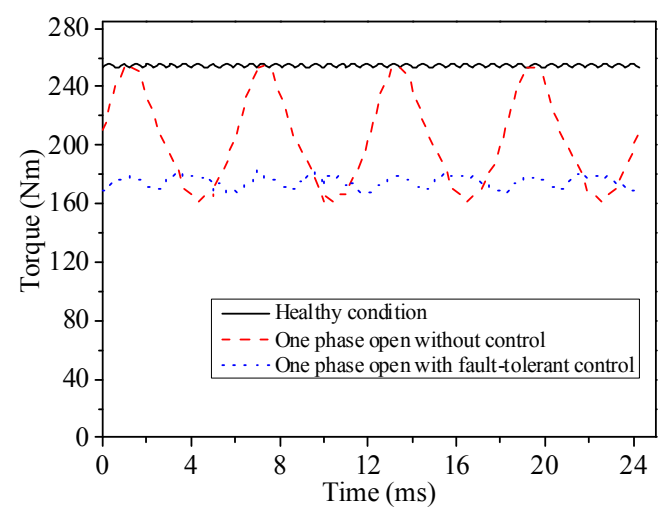

(b) 
Table 5. Machine performances under one-phase-open fault.

\begin{tabular}{|c|c|c|c|c|c|c|c|}
\hline Case & $\begin{array}{l}\text { Rated Speed } \\
(\mathrm{rpm})\end{array}$ & $\begin{array}{l}\text { Torque } \\
(\mathbf{N} \cdot \mathbf{m})\end{array}$ & $\begin{array}{c}\text { Torque Ripple } \\
(\%)\end{array}$ & $\begin{array}{c}\text { Core Loss } \\
\text { (W) }\end{array}$ & $\begin{array}{l}\text { PM Loss } \\
(\mathrm{W})\end{array}$ & $\begin{array}{c}\text { Copper Loss } \\
\text { (W) }\end{array}$ & $\begin{array}{c}\text { Efficiency } \\
(\%)\end{array}$ \\
\hline Healthy & 450 & 254.6 & 0.44 & 71.2 & 247.9 & 373.5 & 94.54 \\
\hline (a) & 450 & 204.2 & 23.38 & 68.1 & 196.3 & 298.8 & 94.47 \\
\hline (b) & 450 & 174.8 & 4.22 & 64.3 & 153.6 & 217.3 & 94.98 \\
\hline
\end{tabular}

Case (a)—Post-fault condition without control; Case (b)—Post-fault condition with fault-tolerant control.

Under healthy conditions, the rated torque is $254.6 \mathrm{~N} \cdot \mathrm{m}$ with a torque ripple of $0.44 \%$. When Phase $\mathrm{E}$ is open-circuited, the output torque reduces to $80 \%$ of the rated torque, and the torque ripple dramatically increases to $23.38 \%$, which is detrimental to the system performance. After adopting the proposed fault-tolerant control strategy, the machine efficiency improves slightly, the output torque decreases to $68.68 \%$ of the rated torque with a torque ripple of $4.22 \%$ and this will enable the EV applications to smoothly operate under reduced load conditions.

\subsection{Two Adjacent-Phases-Open Fault}

Assume Phases D and E are open-circuited, as shown in Figure 15.

Figure 15. Schematic diagram of two adjacent-phases-open fault.

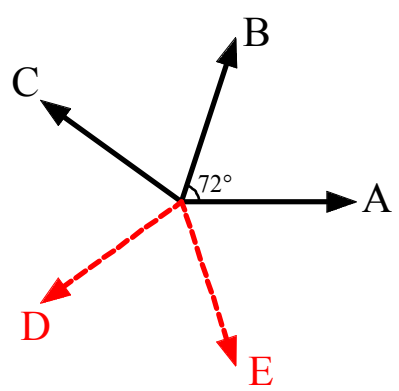

Like the one-phase-open fault condition, the optimal currents for healthy phase windings can be calculated by minimizing a cost function of copper loss:

$$
P_{w}=\sum_{j=0}^{2}\left(i_{j}\right)^{2}+\lambda\left[T_{d}-\frac{1}{\omega} \sum_{j=0}^{2} E_{0} \cos \left(\theta-j \frac{2 \pi}{5}\right) i_{j}\right]
$$

where $j=0,1,2$ represent Phases A, B and C, respectively. The problem dealt with fault-tolerant control of two adjacent-phases-open of the unequal-turn winding PMSM is transformed into a conditional extreme problem. Based on the Lagrange multiplier method, Equation (7) is obtained:

$$
\left[\begin{array}{cccc}
2 & 0 & 0 & -\frac{E_{0}}{\omega} \cos \theta \\
0 & 2 & 0 & -\frac{E_{0}}{\omega} \cos \left(\theta-\frac{2 \pi}{5}\right) \\
0 & 0 & 2 & -\frac{E_{0}}{\omega} \cos \left(\theta-\frac{4 \pi}{5}\right) \\
\frac{E_{0}}{\omega} \cos \theta & \frac{E_{0}}{\omega} \cos \left(\theta-\frac{2 \pi}{5}\right) & \frac{E_{0}}{\omega} \cos \left(\theta-\frac{4 \pi}{5}\right) & 0
\end{array}\right]\left[\begin{array}{c}
i_{a} \\
i_{b} \\
i_{c} \\
\lambda
\end{array}\right]=\left[\begin{array}{c}
0 \\
0 \\
0 \\
T_{d}
\end{array}\right]
$$


Through solving Equation (7), the optimal currents for healthy phase windings are obtained:

$$
\left[\begin{array}{l}
i_{a} \\
i_{b} \\
i_{c}
\end{array}\right]=\left[\begin{array}{c}
\frac{2 \omega T_{d} \cos (\theta)}{E_{0}[3+2 \cos (2 \pi / 5) \cos (2 \theta-\pi / 5)+\cos (2 \theta+\pi / 5)]} \\
\frac{2 \omega T_{d} \cos (\theta-2 \pi / 5)}{E_{0}[3+2 \cos (2 \pi / 5) \cos (2 \theta-\pi / 5)+\cos (2 \theta+\pi / 5)]} \\
\frac{2 \omega T_{d} \cos (\theta+2 \pi / 5)}{E_{0}[3+2 \cos (2 \pi / 5) \cos (2 \theta-\pi / 5)+\cos (2 \theta+\pi / 5)]}
\end{array}\right]
$$

In this case, peak values of the calculated phase currents for healthy phase windings are also adjusted proportionally so that they can be the same as the ones before faults happened. The currents for healthy phase windings and the torque behaviors are calculated and verified by FEA, as shown in Figure 16 and Table 6.

Figure 16. Phase currents and electromagnetic torque under two adjacent-phases-open fault: (a) currents for healthy phase windings; (b) torque.

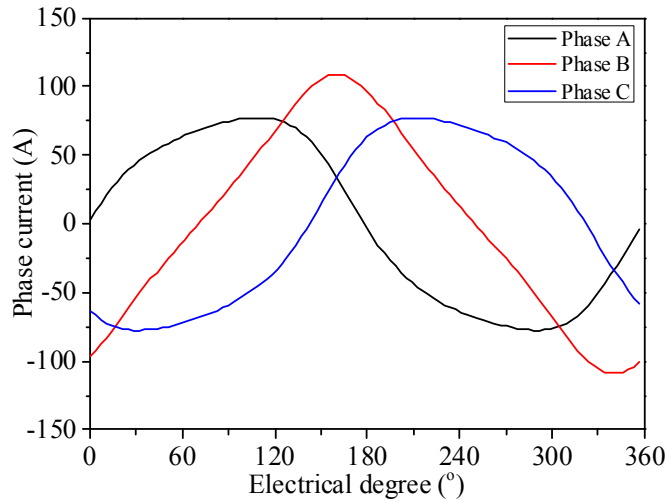

(a)

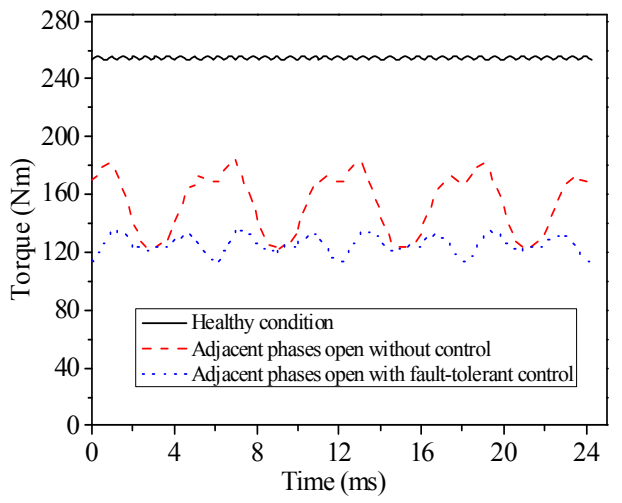

(b)

Table 6. Machine performances under two adjacent-phases-open fault.

\begin{tabular}{cccccccc}
\hline Case & $\begin{array}{c}\text { Rated Speed } \\
(\mathbf{r p m})\end{array}$ & $\begin{array}{c}\text { Torque } \\
\mathbf{( N \cdot m )}\end{array}$ & $\begin{array}{c}\text { Torque } \\
\text { Ripple } \mathbf{( \% )}\end{array}$ & $\begin{array}{c}\text { Core Loss } \\
\mathbf{( W )}\end{array}$ & $\begin{array}{c}\text { PM Loss } \\
(\mathbf{W})\end{array}$ & $\begin{array}{c}\text { Copper Loss } \\
\text { (W) }\end{array}$ & $\begin{array}{c}\text { Efficiency } \\
(\%)\end{array}$ \\
\hline \multirow{2}{*}{ Healthy } & 450 & 254.6 & 0.44 & 71.2 & 247.9 & 373.5 & 94.54 \\
(a) & 450 & 154.1 & 20.76 & 64.7 & 141.7 & 224.1 & 94.4 \\
(b) & 450 & 125.5 & 9.15 & 62.2 & 98.9 & 144.5 & 95.09 \\
\hline
\end{tabular}

Case (a) - Post-fault condition without control; Case (b) - Post-fault condition with fault-tolerant control.

As Phases D and E are open-circuited, the output torque reduces to $60.5 \%$ of the rated torque, and the torque ripple increases to $20.76 \%$, which is detrimental to the system performance. After adopting the proposed fault-tolerant control strategy, the machine efficiency exceeds $95 \%$, and the output torque further reduces to $49.28 \%$ of the rated torque with a torque ripple of $9.15 \%$. In fact, part of the output electromagnetic power is sacrificed to obtain a smooth output torque, but the driving comfort of the EVs is significantly improved. 


\subsection{Two Non-Adjacent-Phases-Open Fault}

Assume Phases C and E are open-circuited, as shown in Figure 17.

Figure 17. Schematic diagram of two non-adjacent-phases-open fault.

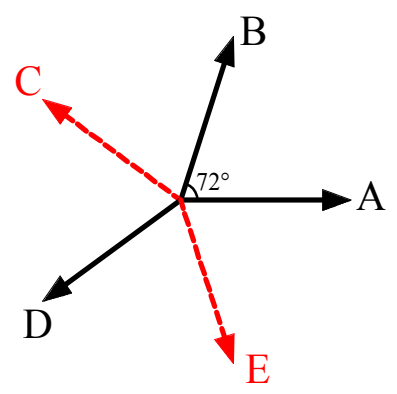

It is similar to the two adjacent-phases-open fault condition that the optimal currents for healthy phase windings can be calculated by minimizing a cost function of copper loss:

$$
P_{w}=\sum_{j=0,1,3}\left(i_{j}\right)^{2}+\lambda\left[T_{d}-\frac{1}{\omega} \sum_{j=0,1,3} E_{0} \cos \left(\theta-j \frac{2 \pi}{5}\right) i_{j}\right]
$$

where $j=0,1,3$ represent Phases A, B and $\mathrm{D}$, respectively. The problem dealt with fault-tolerant control of two non-adjacent-phases-open of the unequal-turn winding PMSM is transformed into a conditional extreme problem. Based on the Lagrange multiplier method, Equation (10) is obtained:

$$
\left[\begin{array}{cccc}
2 & 0 & 0 & -\frac{E_{0}}{\omega} \cos \theta \\
0 & 2 & 0 & -\frac{E_{0}}{\omega} \cos \left(\theta-\frac{2 \pi}{5}\right) \\
0 & 0 & 2 & -\frac{E_{0}}{\omega} \cos \left(\theta+\frac{4 \pi}{5}\right) \\
\frac{E_{0}}{\omega} \cos \theta & \frac{E_{0}}{\omega} \cos \left(\theta-\frac{2 \pi}{5}\right) & \frac{E_{0}}{\omega} \cos \left(\theta+\frac{4 \pi}{5}\right) & 0
\end{array}\right]\left[\begin{array}{c}
i_{a} \\
i_{b} \\
i_{d} \\
\lambda
\end{array}\right]=\left[\begin{array}{c}
0 \\
0 \\
0 \\
T_{d}
\end{array}\right]
$$

Through solving Equation (10), the optimal currents for healthy phase windings are obtained:

$$
\left[\begin{array}{c}
i_{a} \\
i_{b} \\
i_{d}
\end{array}\right]=\left[\begin{array}{c}
\frac{2 \omega T_{d} \cos (\theta)}{E_{0}[3+2 \cos (2 \pi / 5) \cos (2 \theta-\pi / 5)+\cos (2 \theta-\pi / 5)]} \\
\frac{2 \omega T_{d} \cos (\theta-2 \pi / 5)}{E_{0}[3+2 \cos (2 \pi / 5) \cos (2 \theta-\pi / 5)+\cos (2 \theta-\pi / 5)]} \\
\frac{2 \omega T_{d} \cos (\theta+4 \pi / 5)}{E_{0}[3+2 \cos (2 \pi / 5) \cos (2 \theta-\pi / 5)+\cos (2 \theta-\pi / 5)]}
\end{array}\right]
$$

In this case, peak values of the calculated phase currents for healthy phase windings are also adjusted proportionally so that they can be the same as the ones before faults happened. The currents for healthy phase windings and the torque behaviors are calculated and verified by FEA, as shown in Figure 18 and Table 7. 
Figure 18. Phase currents and electromagnetic torque under two non-adjacent-phases-open fault: (a) currents for healthy phase windings; (b) torque.

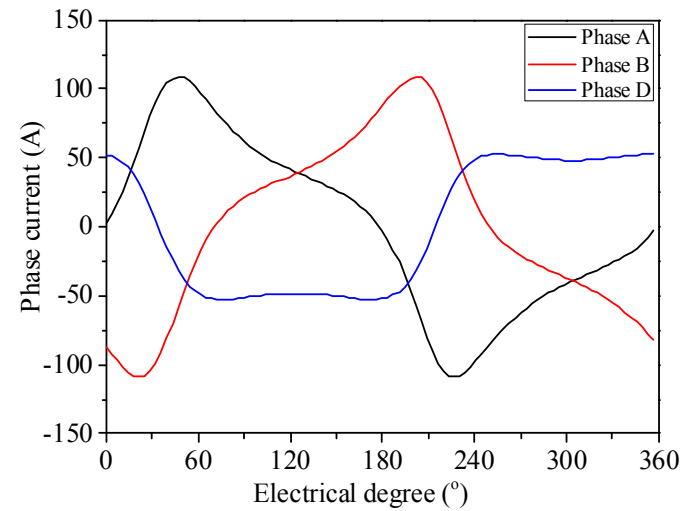

(a)

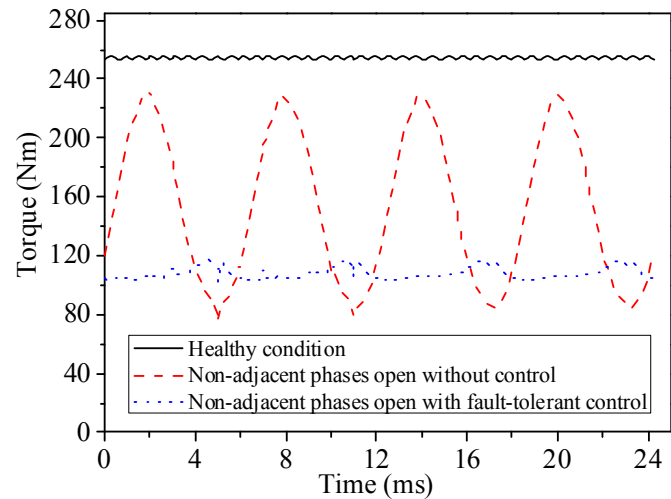

(b)

Table 7. Machine performance under two non-adjacent-phases-open fault.

\begin{tabular}{|c|c|c|c|c|c|c|c|}
\hline Case & $\begin{array}{c}\text { Rated Speed } \\
\text { (rpm) }\end{array}$ & $\begin{array}{l}\text { Torque } \\
(\mathbf{N} \cdot \mathbf{m})\end{array}$ & $\begin{array}{c}\text { Torque Ripple } \\
(\%)\end{array}$ & $\begin{array}{c}\text { Core Loss } \\
(\mathbf{W})\end{array}$ & $\begin{array}{c}\text { PM Loss } \\
(\mathbf{W})\end{array}$ & $\begin{array}{c}\text { Copper Loss } \\
\text { (W) }\end{array}$ & $\begin{array}{c}\text { Efficiency } \\
(\%)\end{array}$ \\
\hline Healthy & 450 & 254.6 & 0.44 & 71.2 & 247.9 & 373.5 & 94.54 \\
\hline (a) & 450 & 153.1 & 51.43 & 64.6 & 148.8 & 224.1 & 94.32 \\
\hline (b) & 450 & 108.1 & 6.86 & 65.2 & 117.8 & 122.2 & 94.35 \\
\hline
\end{tabular}

Case (a) - Post-fault condition without control; Case (b)_-Post-fault condition with fault-tolerant control.

As Phases $\mathrm{C}$ and $\mathrm{E}$ are open-circuited, the output torque reduces to $60.1 \%$ of the rated torque, and the torque ripple dramatically increases to $51.43 \%$, which is detrimental to the system performance. After adopting the proposed fault-tolerant control strategy, the machine efficiency slightly decreases compared with the healthy condition, the output torque reduces to $42.46 \%$ of the rated torque, and it is $108.1 \mathrm{~N} \cdot \mathrm{m}$ with a torque ripple of $6.86 \%$, the torque ripple is significantly reduced, and this will enable the EV applications to smoothly operate under reduced load conditions. The comprehensive comparison of the machine performances under different operating conditions are listed, as shown in Table 8 . The per unit values of Table 8 are shown in Table 9.

Table 8. Machine performances in healthy, fault and fault-tolerant control modes.

\begin{tabular}{ccccc}
\hline Case & & Torque (Nm) & Torque ripple (\%) & Efficiency (\%) \\
\hline Healthy condition & & 254.6 & 0.44 & 94.54 \\
\hline \multirow{2}{*}{ One-phase-open } & (a) & 204.2 & 23.38 & 94.47 \\
\cline { 2 - 5 } & (b) & 174.8 & 4.22 & 94.98 \\
\hline \multirow{2}{*}{ Adjacent-phases-open } & (a) & 154.1 & 20.76 & 94.4 \\
\cline { 2 - 5 } & (b) & 125.5 & 9.15 & 95.09 \\
\hline \multirow{2}{*}{ Non-adjacent-phases-open } & (a) & 153.1 & 51.43 & 94.32 \\
\cline { 2 - 5 } & (b) & 108.1 & 6.86 & 94.35 \\
\hline
\end{tabular}

Case (a)_-Post-fault condition without control; Case (b)_-Post-fault condition with fault-tolerant control. 
Table 9. Machine performances in healthy, fault and fault-tolerant control modes using per unit value.

\begin{tabular}{ccccc}
\hline Case & & Torque (p.u.) & Torque ripple (p.u.) & Efficiency (p.u.) \\
\hline Healthy condition & & 1.0 & 1.0 & 1.0 \\
\hline \multirow{2}{*}{ One-phase-open } & (a) & 0.802 & 53.14 & 0.999 \\
\cline { 2 - 5 } & (b) & 0.687 & 9.59 & 1.005 \\
\hline \multirow{2}{*}{ Adjacent-phases-open } & (a) & 0.605 & 47.18 & 0.999 \\
\cline { 2 - 5 } & (b) & 0.493 & 20.8 & 1.006 \\
\hline \multirow{2}{*}{ Non-adjacent-phases-open } & (a) & 0.601 & 116.89 & 0.998 \\
\cline { 2 - 5 } & (b) & 0.425 & 15.59 & 0.998 \\
\hline
\end{tabular}

Case (a) - Post-fault condition without control; Case (b)—Post-fault condition with fault-tolerant control.

Since the electromagnetic power of PMSM equals the sum of instantaneous power of each of the stator windings, so when the machine operates under open-circuits of one or two phases, the output torques drop to 0.8 and 0.6 p.u., respectively, as shown in Tables 8 and 9. For one-phase-open, two adjacent-phases-open, and two non-adjacent-phases-open faults, after adoption of the proposed fault-tolerant control strategies, the torques decrease to $0.687,0.493$ and 0.425 p.u., respectively, but the torque ripples of all conditions are significantly reduced, and the machine efficiencies are even improved in some cases, which indicates that the proposed fault-tolerant control strategies are quite acceptable, with some sacrifice of the electromagnetic power.

\section{Conclusions}

(1) A five-phase 20-slot/22-pole PMSM featured with unequal-turn winding configuration is proposed for EV applications, and an improved slot-vector diagram is developed to calculate winding factors of different order harmonics for the unequal-turn winding configuration.

(2) The winding factor of 2-pole sub harmonic of double-layer winding is lower than that of single-layer winding. And for the unequal-turn winding, through optimization of the turn number of different coil sides, the winding factor of 2-pole sub harmonic is reduced to zero.

(3) The mutual inductances of double-layer winding configuration are larger than those of the single-layer winding configuration, and the mutual inductances of unequal-turn winding configuration are a little larger than those of the double-layer winding configuration, among the three investigated schemes, the unequal-turn winding scheme features least load radial force density harmonics, lowest PM loss and highest efficiency.

(4) The fault-tolerant control strategies for open-circuits of one and two phases are discussed. Under these control strategies, the torque ripples are significantly reduced, with some sacrifice of the electromagnetic power, and this will enable the EV applications to smoothly operate under reduced load conditions.

\section{Acknowledgments}

This work was supported in part by the 863 Plan of China under Project 2011AA11A261, and in part by National Natural Science Foundation of China under Projects 51077026, 51325701, and 51377033. 


\section{Conflicts of Interest}

The authors declare no conflict of interest.

\section{References}

1. EL-Refaie, A.M. Fractional-slot concentrated-windings synchronous permanent magnet machines: Opportunities and challenges. IEEE Trans. Ind. Electron. 2010, 57, 107-121.

2. Wang, J.B.; Yuan, X.B.; Atallah, K. Design optimization of a surface-mounted permanent-magnet motor with concentrated windings for electric vehicle applications. IEEE Trans. Veh. Technol. 2013, 62, 1053-1064.

3. Tangudu, J.K.; Jahns, T.M.; Bobn, T.P. Design, analysis and loss minimization of a fractional-slot concentrated winding IPM machine for traction applications. In Proceedings of the 2011 IEEE Energy Conversion Congress and Exposition (ECCE), Phoenix, AZ, USA, 17-22 September 2011; pp. 2236-2243.

4. Chen, Q.; Liu, G.H.; Gong, W.S.; Zhao, W.X. A new fault-tolerant permanent-magnet machine for electric vehicle applications. IEEE Trans. Magn. 2011, 47, 4183-4186.

5. Parsa, L.; Toliyat, H. Fault-tolerant interior-permanent-magnet machines for hybrid electric vehicle applications. IEEE Trans. Veh. Technol. 2007, 56, 1546-1552.

6. Reddy, P.B.; EL-Refaie, A.M.; Kum-Kang, H.; Tangudu, J.K.; Jahns, T.M. Comparison of interior and surface PM machines equipped with fractional-slot concentrated windings for hybrid traction applications. IEEE Trans. Energy Convers. 2012, 27, 593-602.

7. Chung, S.U.; Kim, J.M.; Koo, D.H.; Woo, B.C.; Hong, D.K.; Lee, J.Y. Fractional slot concentrated winding permanent magnet synchronous machine with consequent pole rotor for low speed direct drive. IEEE Trans. Magn. 2012, 48, 2965-2968.

8. Shah, M.R.; EL-Refaie, A.M. End Effects in Multiphase Fractional Slot Concentrated-winding surface permanent magnet synchronous machines. IEEE Trans. Energy Convers. 2010, 25, 1001-1009.

9. Donato, G.D.; Capponi, F.G.; Caricchi, F. Fractional-slot concentrated-winding axial-flux permanent-magnet machine with core-wound coils. IEEE Trans. Ind. Appl. 2012, 48, 630-641.

10. Barcaro, M.; Bianchi, N.; Magnussen, F. Remarks on torque estimation accuracy in fractional-slot permanent-magnet motors. IEEE Trans. Ind. Electron. 2012, 59, 2565-2572.

11. El-Refaie, A.M. Fault-tolerant permanent magnet machines: A review. IET Electr. Power Appl. 2011, 5, 59-74.

12. Merow, B.C.; Jack, A.G.; Atkinson, D.J.; Green, S.R.; Atkinson, G.J.; King, A.; Green, B. Design and testing of a four-phase fault-tolerant permanent-magnet machine for an engine fuel pump. IEEE Trans. Energy Convers. 2004, 19, 671-677.

13. Bianchi, N.; Pre, M.D.; Bolognani, S. Design considerations on fractional-slot fault-tolerant synchronous motors. In Proceedings of the IEEE International Conference on Electric Machines and Drives, San Antonio, TX, USA, 15-18 May 2005; pp. 902-909. 
14. Abolhassani, M.T.; Toliyat, H.A. Fault tolerant permanent magnet motor drives for electric vehicles. In Proceedings of the IEEE International Electric Machines and Drives Conference, Miami, FL, USA, 3-6 May 2009; pp. 1146-1152.

15. Aslan, B.; Semail, E.; Korecki, J.; Legranger, J. Slot/pole combinations choice for concentrated multiphase machines dedicated to mild-hybrid applications. In Proceedings of the 37th Annual Conference on IEEE Industrial Electronics Society (IECON 2011), Melbourne, Australia, 7-10 November 2011; pp. 3698-3703.

16. Fornasiero, E.; Alberti, L.; Bianchi, N.; Bolognani, S. Considerations on selecting fractional-slot nonoverlapped coil windings. IEEE Trans. Ind. Appl. 2013, 49, 1316-1324.

17. Bianchi, N.; Fornasiero, E. Impact of MMF space harmonic on rotor losses in fractional-slot permanent-magnet machines. IEEE Trans. Energy Convers. 2009, 24, 323-328.

18. Bianchi, N.; Fornasiero, E. An index of rotor losses in three-phase fractional-slot permanent magnet machines. IET Electr. Power Appl. 2009, 3, pp. 381-388.

19. Aslan, B.; Semail, E.; Legranger, J. General analytical model of magnet average eddy-current volume losses for comparison of multiphase PM machines with concentrated winding. IEEE Trans. Energy Convers. 2014, 29, 72-83.

20. Aslan, B.; Semail, E.; Legranger, J. Analytical model of magnet eddy-current volume losses in multi-phase PM machines with concentrated winding. In Proceedings of the 2012 IEEE Energy Conversion Congress and Exposition (ECCE), Raleigh, NC, USA, 15-20 September 2012; pp. 3371-3378.

21. Raminosoa, T.; Gerada, C.; Othman, N.; Lillo, L.D. Rotor losses in fault-tolerant permanent magnet synchronous machines. IET Electr. Power Appl. 2011, 5, 75-88.

22. Fornasiero, E.; Bianchi, N.; Bolognani, S. Slot Harmonic impact on rotor losses in fractional-slot permanent-magnet machines. IEEE Trans. Ind. Appl. 2012, 59, 2557-2564.

23. Wang, J.B.; Xia, Z.P.; Long, S.A.; Howe, D. Radial force density and vibration characteristics of modular permanent magnet brushless AC machine. IEE Proc. Electr. Power Appl. 2006, 153, 793-801.

24. Wang, J.B.; Xia, Z.P.; Howe, D.; Long, S.A. Vibration characteristics of modular permanent magnet brushless AC machines. In Proceedings of the 41st IEEE IAS Annual Meeting Conference, Tampa, FL, USA, 8-12 October 2006; pp. 1501-1506.

25. Zhu, Z.Q.; Xia, Z.P.; Wu, L.J.; Jewell, G.W. Analytical modeling and finite-element computation of radial vibration force in fractional-slot permanent-magnet brushless machines. IEEE Trans. Ind. Appl. 2010, 46, 1908-1918.

26. Zhu, Z.Q.; Xia, Z.P.; Wu, L.J.; Jewell, G.W. Influence of slot and pole number combination on radial force and vibration modes in fractional slot PM brushless machines having single- and double-layer windings. In Proceedings of the IEEE Energy Conversion Congress and Exposition (ECCE), San Jose, CA, USA, 20-24 September 2009; pp. 3443-3450.

27. Kometani, H.; Asao, Y.; Adachi, K. Dynamo-Electric Machine. U.S. Patent 6,166,471, 26 December 2000.

28. Ito, K.; Naka, K.; Nakano, M.; Kobayashi, M. Electric Machine. U.S. Patent 7,605,514, 20 October 2009. 
29. Cistelecan, M.V.; Ferreira, F.J.T.E.; Popescu, M. Three phase tooth-concentrated multiple-layer fractional windings with low space harmonic content. In Proceedings of the 2010 IEEE on Energy Conversion Congress and Exposition (ECCE), Atlanta, GA, USA, 12-16 September 2010; pp. 1399-1405.

30. Dajaku, G.; Gerling, D. A novel 24-slots/10-poles winding topology for electric machines. In Proceedings of the International Electric Machines and Drives Conference (IEMDC-2011), Niagara Falls, ON, Canada, 15-18 May 2011; pp. 65-70.

31. Dajaku, G.; Gerling, D. Eddy current loss minimization in rotor magnets of PM machines using high-efficiency 12-teeth/10-slots winding topology. In Proceedings of the International Conference on Electrical Machines and Systems 2011, Beijing, China, 20-23 August 2011; pp. 1-6.

32. Staunton, R.H.; Ayers, C.W.; Marlino, L.D.; Chiasson, J.N.; Burress, T.A. Evaluation of 2004 Toyota Prius Hybrid Electric Drive System; Oak Ridge National Laboratory: Oak Ridge, TN, USA, 2006.

33. Ifedi, C.J.; Mecrow, B.C.; Brockway, S.T.M.; Boast, G.S.; Atkinson, G.J.; Kostic-Perovic, D. Fault tolerant in-wheel motor topologies for high performance electric vehicles. In Proceedings of the 2011 IEEE International Electric Machines \& Drives Conference (IEMDC), Niagara Falls, ON, Canada, 15-18 May 2011; pp. 1310-1315.

34. Ifedi, C.J.; Mecrow, B.C.; Widmer, J.D.; Atkinson, G.J.; Brockway, S.T.M.; Kostic-Perovic, D. A high torque density, direct drive in-wheel motor for electric vehicles. In Proceedings of the 6th IET International Conference on Power Electronics, Machines and Drives (PEMD 2012), Bristol, UK, 27-29 March 2012; pp. 1-6.

35. Rix, A.J.; Kamper, M.J. Radial-flux permanent-magnet hub drives: A comparison based on stator and rotor topologies. IEEE Trans. Ind. Electron. 2012, 59, 2475-2483.

36. Zheng, P.; Sui, Y.; Zhao, J.; Tong, C.D.; Lipo, T.A.; Wang, A.M. Investigation of a novel five-phase modular permanent-magnet in-wheel motor. IEEE Trans. Magn. 2011, 47, 4084-4087.

(C) 2014 by the authors; licensee MDPI, Basel, Switzerland. This article is an open access article distributed under the terms and conditions of the Creative Commons Attribution license (http://creativecommons.org/licenses/by/3.0/). 